\title{
Synthesis and Characterization of Molybdenum Disulfide Nanoflowers and Nanosheets: Nanotribology
}

\author{
S. V. Prabhakar Vattikuti and Chan Byon \\ School of Mechanical Engineering, Yeungnam University, Gyeongsan 712-749, Republic of Korea \\ Correspondence should be addressed to Chan Byon; cbyon@ynu.ac.kr
}

Received 20 March 2015; Accepted 4 May 2015

Academic Editor: Xiaogang Han

Copyright (C) 2015 S. V. P. Vattikuti and C. Byon. This is an open access article distributed under the Creative Commons Attribution License, which permits unrestricted use, distribution, and reproduction in any medium, provided the original work is properly cited.

\begin{abstract}
This paper reports the solvothermal synthesis of $\mathrm{MoS}_{2}$ nanoflowers and nanosheets. The nanoflowers have a mean diameter of about $100 \mathrm{~nm}$ and were obtained using thioacetamide $\left(\mathrm{C}_{2} \mathrm{H}_{5} \mathrm{NS}\right)$ as a sulfur source. The few layered nanosheets were obtained using thiourea $\left(\mathrm{CH}_{4} \mathrm{~N}_{2} \mathrm{~S}\right)$ as a sulfur source. The obtained powders were characterized using powder X-ray diffraction (XRD), scanning electron microscopy (SEM) with energy dispersive spectroscopy (EDS), and transmission electron microscopy (TEM). The lubricating effect of $\mathrm{MoS}_{2}$ nanoflowers and nanosheets were analyzed using four-ball test, the topography of the wear scar was analyzed using SEM, EDS, and 3D surface profilometry. The relationship between the tribological properties and morphology of the materials was determined. It is observed that the engine oil containing the $\mathrm{MoS}_{2}$ nanomaterials penetrated more easily into the interface space, and it formed a continuous film on the interface surface. The tribological performance showed that the synthesized nanosheets had superior antiwear and friction-reducing properties as a lubrication additive compared with nanoflowers. Also, the wear scar of balls lubricated with nanoflowers revealed a larger diameter compared to nanosheets. In conclusion, nanosheets dispensed in oil have better tribological performance compared to nanoflowers oil in terms of capability to reduce friction.
\end{abstract}

\section{Introduction}

Two-dimensional (2D) and three-dimensional (3D) functional nanostructured materials have received great attention due to their inherent physicochemical properties, such as high specific surface-to-volume ratio, anisotropy, chemical inertness, photocorrosion resistance, and excellent tribological performance $[1,2]$. Such materials are applicable in various fields, including lubricants, energy storage, field-effect transistors, and catalysis [1-4]. Novel lubricants containing nanoparticles could provide extended reliability and major energy savings in severe friction and wear conditions, which would impact industries related to sustainable engineering of heavy equipment and support energy self-reliance [5-10].

Tenne et al. discovered spherical fullerene-like nanoparticles of $\mathrm{MoS}_{2}$ and $\mathrm{WS}_{2}$ nanotubes in 1992 [11]. $\mathrm{MX}_{2}(\mathrm{M}=\mathrm{Mo}$, $\mathrm{W}$ and $\mathrm{X}=\mathrm{S}, \mathrm{Se}$ ) are well known for their solid-lubrication properties. Molybdenum disulfide $\left(\mathrm{MoS}_{2}\right)$ has a layered hexagonal crystal structure, which is mostly important for solid lubrication or as an additive for lubricating oils [12-14]. These materials offer low shear resistance to any applied shear stress due to their layered structure with strong intralayer covalent bonds and weak interlayer van der Waals bonds, which decreases friction between interfaces [15].

These materials exist in numerous forms, such as fullerene-like nanoparticles, flake-like structures, and nanotubes $[16,17]$. These materials are suitable for adding to lubrication fluids. $\mathrm{MoS}_{2}$ nanoparticles perform very well in boundary-lubricated contact, particularly with steels [18-20]. However, the key parameters under different contact conditions with respect to morphology have yet to be determined. Lubricants mixed with nanoparticles are known to be the most effective approach to reducing the friction and wear at contact interfaces; however, the presence of solid particles may also lead to oil starvation for lubrication regimes [21].

Explaining the tribological performance of inorganic nanomaterials depends upon several mechanisms and effects: (a) rolling friction [22], (b) the inorganic nanoparticles acting as spacers to prevent direct contact between the asperities [23], and (c) third-body material transfer to form a thin lubricious film $[24,25]$. However, the efficiency of the lubrication mechanism depends on various conditions and 
intrinsic characteristics, including the morphology, crystal structure, shape, and size of the particular nanoparticles. For example, in the case of fullerene-like $\mathrm{MoS}_{2}$ nanoparticles, different modes of deformation and destruction are exhibited when in contact with surfaces [18]. Kalin et al. demonstrated that the adhesion of thin $\mathrm{MoS}_{2}$ nanosheets on a surface has four possible mechanisms: (i) exfoliation of individual nanotubes into nanosheets due to shear stress, (ii) nanosheet aggregation, (iii) nanotube deformation at the surface, and (iv) some nanotubes being damaged [26]. However, these mechanisms have been difficult to prove.

The main negative aspect of a nanofluid is sedimentation of the dispersed particles in the fluid due to poor compatibility between the dissimilar phases. This poses a problem of deteriorating the tribological properties of nanofluids [27, 28] due to small gaps between the asperities: the supply of nanoparticles to the contact is inadequate or interrupted at high contract loads in the boundary-lubricant regime [26]. It is believed that better lubrication is maintained only through the entrapment of multilayered or flake-like solid particles. Useful tribological properties have also been ascribed to their structure, such as chemical inertness and longevity. However, experimental confirmation of the tribological properties (and thus the lubrication mechanisms) of inorganic $\mathrm{MoS}_{2}$ flakelike nanoparticles has remained limited.

Recently, various synthesis processes have been developed to prepare $\mathrm{MoS}_{2}$ nanomaterials, including chemical vapor deposition (CVD), thermal reduction, high-temperature sulfurization, laser ablation, and sol-gel methods [2735]. Using these approaches, different morphologies (fullerene-like, nanotube, nanosphere, and nanorods) have been tested and used in practical applications. However, the synthesis methods generally require complex technologies and harmful organic surfactants. The solvothermal method has attracted much interest due to its versatility and potential to fabricate nanoparticles for applications.

To the best of our knowledge, there have been limited reports using solvothermal methods to control the morphology and properties of $\mathrm{MoS}_{2}$ nanomaterials with proper selection of the sulfur source. We report an optimized procedure for solvothermal synthesis of $\mathrm{MoS}_{2}$ nanoflowers and nanosheets assembled with a few lamellar layers. Thioacetamide and thiourea were used as the respective sulfur sources. The aim of this work is to investigate the lubricating and antiwear behavior of the synthesized $\mathrm{MoS}_{2}$ materials. The materials were tested under the same conditions in dispersion in engine oil and in the boundary lubrication regime. The tribofilm and wear debris were characterized to understand the lubrication mechanisms. In addition, the optical properties and band energies of these $\mathrm{MoS}_{2}$ materials are reported.

\section{Experimental Procedure}

In order to obtain the optimal conditions for synthetic procedure, a series of trials were carried out. All the chemicals were used in this synthesis without further filtration. Figure 1 shows a schematic diagram of the synthesis procedure and formation of $\mathrm{MoS}_{2}$ nanoflowers and nanosheets.
2.1. Preparation of Nanoflowers. To obtain the $\mathrm{MoS}_{2}$ flowerlike structure, ammonium heptamolybdate tetrahydrate $\left(\left(\mathrm{NH}_{4}\right)_{6} \mathrm{Mo}_{7} \mathrm{O}_{24} \cdot 4 \mathrm{H}_{2} \mathrm{O}\right)$, citric acid $\left(\mathrm{C}_{6} \mathrm{H}_{8} \mathrm{O}_{7}\right)$, and thioacetamide $\left(\mathrm{C}_{2} \mathrm{H}_{5} \mathrm{NS}\right)$ were used as the starting materials and the sulfur source. The synthesis methodology was performed with an optimized molar ratio of Mo to citric acid of $1: 2$. Starting, $1.4 \mathrm{~g}$ of ammonium heptamolybdate tetrahydrate and $0.61 \mathrm{~g}$ of citric acid were dissolved in distilled water under magnetic stirring and kept at $130^{\circ} \mathrm{C}$ on a hot plate for $25 \mathrm{~min}$. The suspension was continuously stirred and refluxed with a final $\mathrm{pH}$ of 4 . Then, $2.36 \mathrm{~mL}$ of thioacetamide in water was added dropwise to the solution. Finally, the precipitate solution was placed in a Teflon-lined stainless-steel autoclave.

2.2. Preparation of Nanosheets. The ammonium heptamolybdate tetrahydrate, citric acid, and thiourea $\left(\mathrm{CH}_{4} \mathrm{~N}_{2} \mathrm{~S}\right)$ were used as the starting materials and the sulfur source to obtain the $\mathrm{MoS}_{2}$ sheet-like structure. Starting, $1.3 \mathrm{~g}$ of ammonium heptamolybdate and $0.49 \mathrm{~g}$ of citric acid were dissolved in distilled water under magnetic stirring and kept at $90^{\circ} \mathrm{C}$ on a hot plate for $25 \mathrm{~min}$. The ammonia water is added to suspension solution with continuous stirring to adjust the $\mathrm{pH}$ at 4 . Then, $1.27 \mathrm{~g}$ of thiourea in water was added dropwise to the solution with continuous stirring on a hot plate for $5 \mathrm{~min}$. Finally, suspension solution was transferred into a $40 \mathrm{~mL}$ Teflon autoclave.

For both samples, the autoclave was maintained at $160^{\circ} \mathrm{C}$ for $10 \mathrm{~h}$. The reactor was cooled to room temperature; the obtained black precipitates were collected by centrifugation and then filtered and washed three times with distilled water and ethanol. The obtained powders were finally dried under vacuum at $140^{\circ} \mathrm{C}$ for $8 \mathrm{~h}$.

2.3. Lubricants Preparation. Experiments were performed using Durasyn-170 oil (polyalphaolefin (PAO)), which is a typical synthetic oil for automotive applications that has a density of $27.7 \mathrm{~kg} / \mathrm{m}^{3}$ at $15^{\circ} \mathrm{C}$. The experiments were carried out with the base oil and with base oil containing 0.05, 0.1, 0.5 , and $1 \mathrm{wt} \%$ of nanoflowers and nanosheets additives. A relatively various concentration of synthesized $\mathrm{MoS}_{2}$ materials was used to determine the effect of morphology on the tribological performance. The suspensions of oil and nanoadditives were thoroughly mixed with a magnetic stirrer for 3 hours. The $\mathrm{MoS}_{2}$ materials were added to the base oil and mixed with hexane, and stability measurement was done using a dynamic light scattering system (Nano ZS (ZEN 3600)). The kinematic viscosity of the oils was observed using an Ultra Programmable Rheometer as per ASTM standards.

2.4. Tribological Tests. The coefficient of friction and wear scar of all samples were studied using a four-ball tribometer. The four-ball test machine is used to estimate the wear preventive characteristics of the lubricant. The test force was kept constant at $40 \mathrm{Kgf}$, and $1000 \mathrm{rpm}$ was applied for 60 minutes at $75^{\circ} \mathrm{C}$. Steel balls with a $12.5 \mathrm{~mm}$ diameter and hardness of HRC 65 were used. The scar diameter of ball serves as a characteristic of the lubricant. In dissipative systems, extreme pressure at contacts is a major issue, depending on 


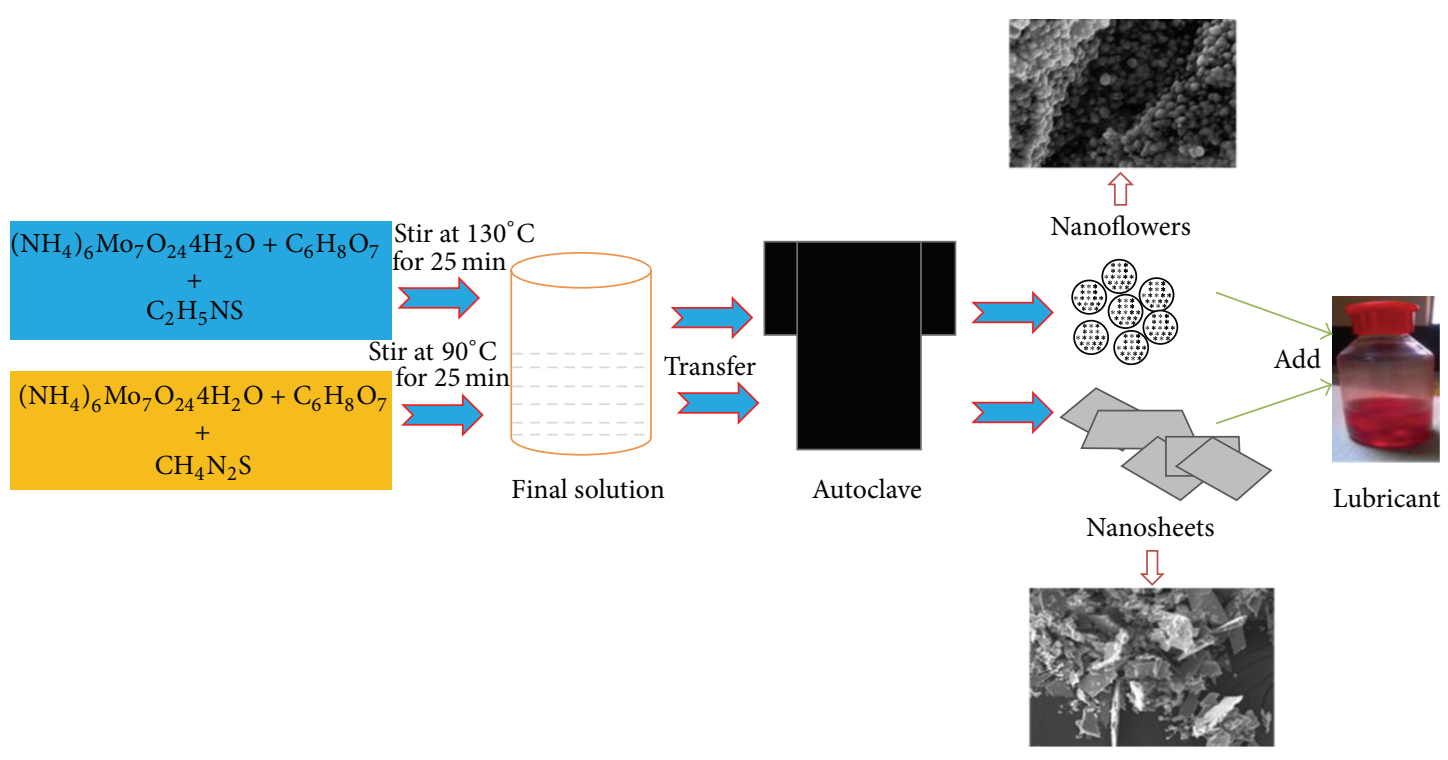

FIGURE 1: Schematic diagram of the formation of $\mathrm{MoS}_{2}$ nanoflowers and nanosheets.

the potential applications, which is why we selected the fourball tribometer for these studies.

The crystalline structure of the samples was estimated using powder X-ray diffraction (XRD) using a Shimadzu Labx XRD 6100 with $\mathrm{Cu}-\mathrm{K} \alpha$ radiation $(\lambda=0.14056 \mathrm{~nm})$. The morphologies of the samples were observed by scanning electron microscopy (SEM) on a Shimadzu Corporation Superscan SSX-550 SEM-EDS. Transmission electron microscope (TEM) analysis of the samples was carried out with a Hitachi $\mathrm{H}-7000$ of $100 \mathrm{KV}$. The phase purity was estimated using a Fourier transform infrared spectroscope (FTIR) (Avatar 370) with a spectral range of $400-4000 \mathrm{~cm}^{-1}$. Thermogravimetry analysis was done using a DTG-60/60H TG/differential thermal analyzer under an argon gas at $900^{\circ} \mathrm{C}$ at a heating rate of $9^{\circ} \mathrm{C}$ per minute. The topography of the wear scar was studied by SEM and 3D surface profilometer. The chemical composition of the tribofilm formed on the worn surfaces of the upper ball was examined using EDS mapping.

\section{Results and Discussion}

The powder X-ray diffraction (XRD) studies were carried out to analyze the crystal structure of the $\mathrm{MoS}_{2}$ nanoparticles as a function of the processing conditions as shown in Figure 2. Both samples exhibit the crystallite nature of $\mathrm{MoS}_{2}$ materials with an XRD pattern indexed at $14^{\circ}, 32^{\circ}, 39.5^{\circ}$, and $58^{\circ}$ corresponding to the (002), (100), (103), and (110) crystal planes of the $\mathrm{MoS}_{2}$ structure, consistent with the corresponding standard card (JCPDS card number 371492). No impurity peaks or other phases were observed.

SEM images (Figures 3(a) and 3(b)) show that the sample obtained with $\mathrm{C}_{2} \mathrm{H}_{5} \mathrm{NS}$ as the sulfur source comprises uniform $\mathrm{MoS}_{2}$ nanoflowers with an average size of $100 \mathrm{~nm}$. The nanoflowers are well defined and rounded with a large amount of agglomeration of open-ended structure. It is

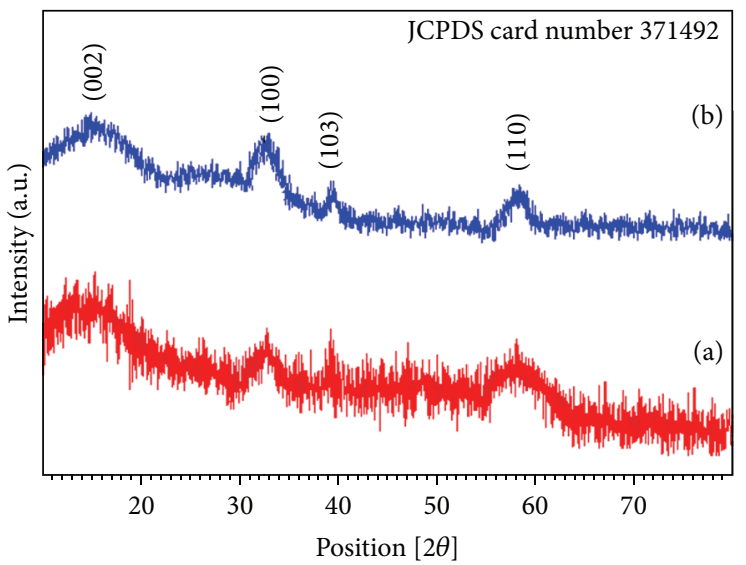

FIGURE 2: XRD patterns of $\mathrm{MoS}_{2}$ : (a) nanoflowers and (b) nanosheets.

believed that this open-ended structure would offer more effective triboactive mechanisms for easy distribution on the interfacing surfaces. Interestingly, the sample obtained using thiourea as the sulfur source formed multilayer nanosheets of a size of a few nanometers, as shown in Figures 3(c) and 3(d) with different magnifications.

TEM images of the nanoflowers are shown with different magnifications in Figures 4(a), 4(b), and 4(c). The images show that the nanoflowers are rounded and loosely connected to each other with a narrow size distribution and regular spherical structure, which is in good agreement with the SEM results. This means that the nanoflowers have well-defined shape and are uniform in both morphology and particle size distribution. Figures 4(d), 4(e), and 4(f) show the structures of the nanosheets with different magnifications. The edge lengths of the nanosheets are controllable at the nanometer scale, typically from $40 \mathrm{~nm}$ to a few tens of nanometers, and their thickness is 10 to $50 \mathrm{~nm}$. 


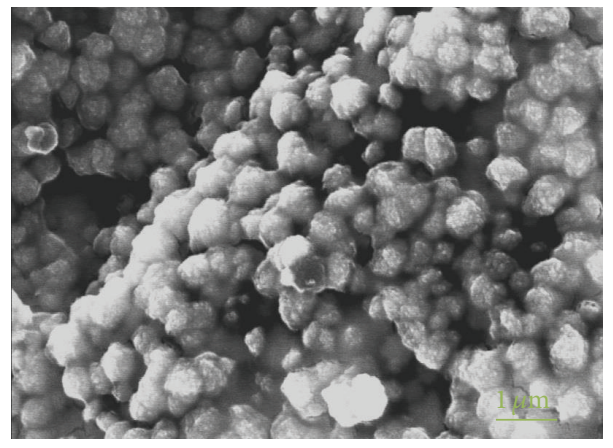

(a)

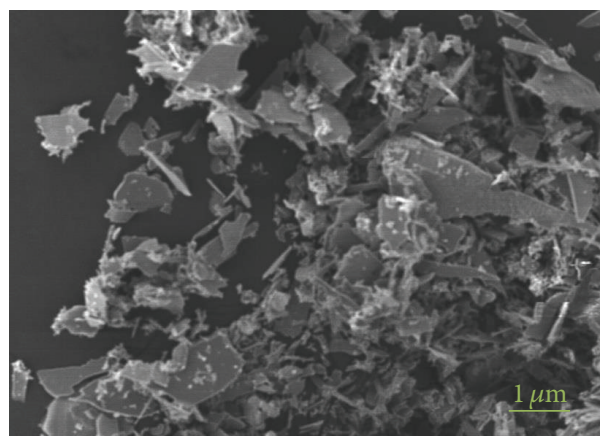

(c)

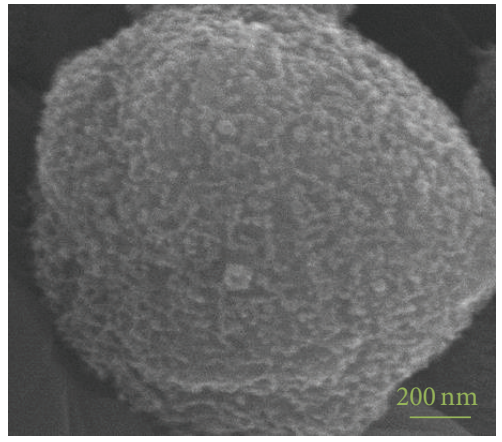

(b)

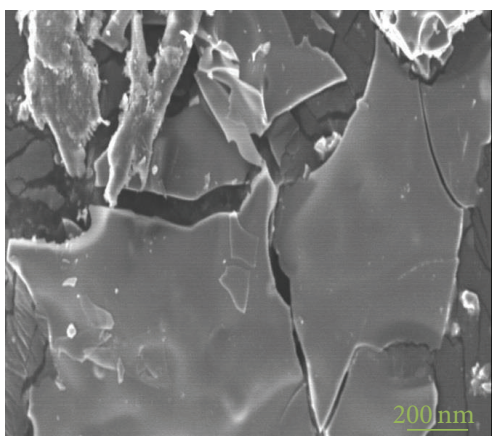

(d)

FIGURE 3: SEM images of $\mathrm{MoS}_{2}$ : ((a) and (b)) nanoflowers and ((c) and (d)) nanosheets.

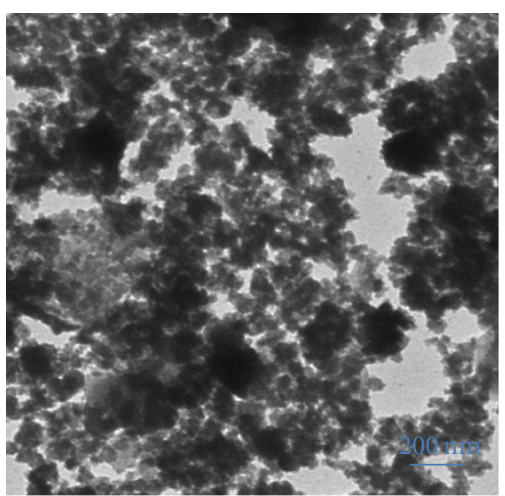

(a)

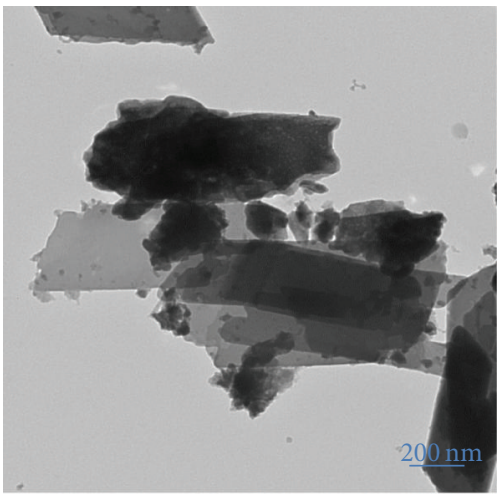

(d)

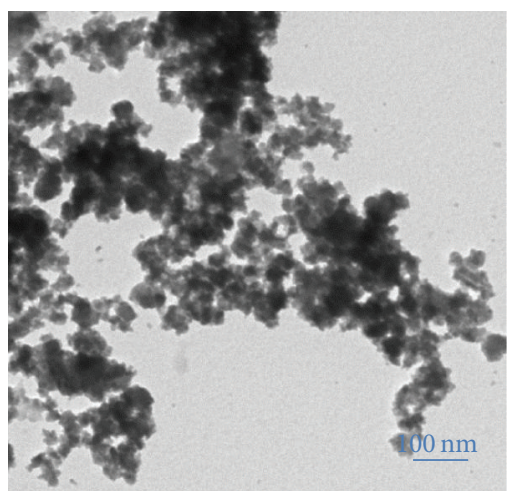

(b)

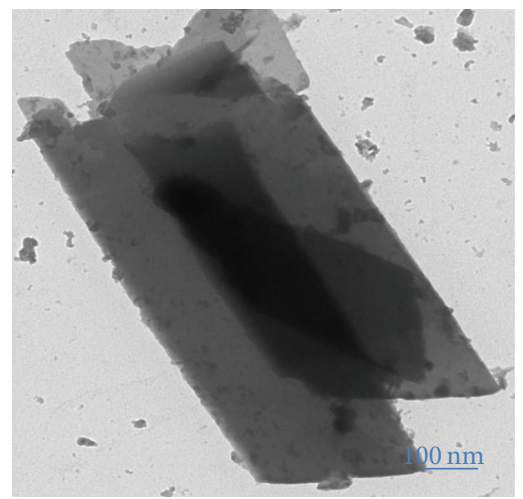

(e)

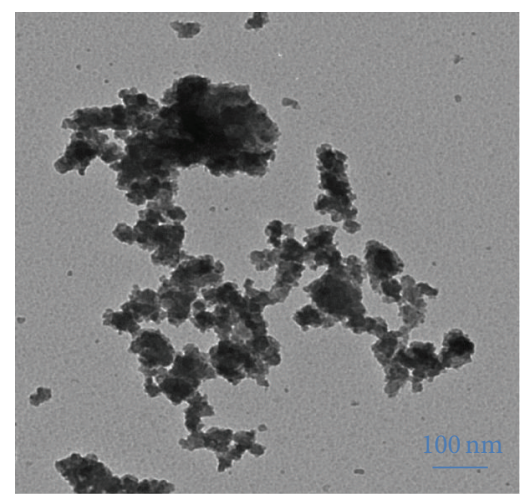

(c)

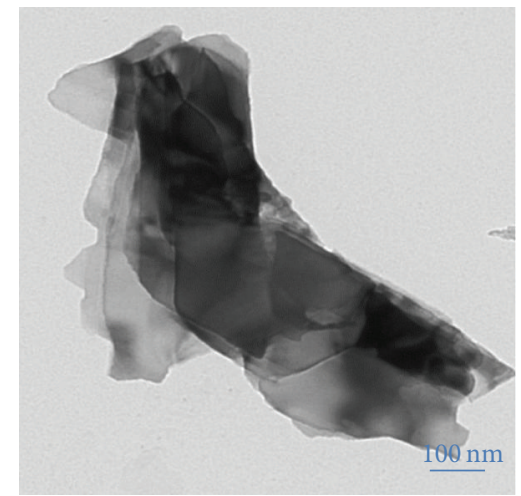

(f)

FIgURE 4: TEM images of $\mathrm{MoS}_{2}$ : ((a), (b), and (c)) nanoflowers and ((d), (e), and (f)) nanosheets. 


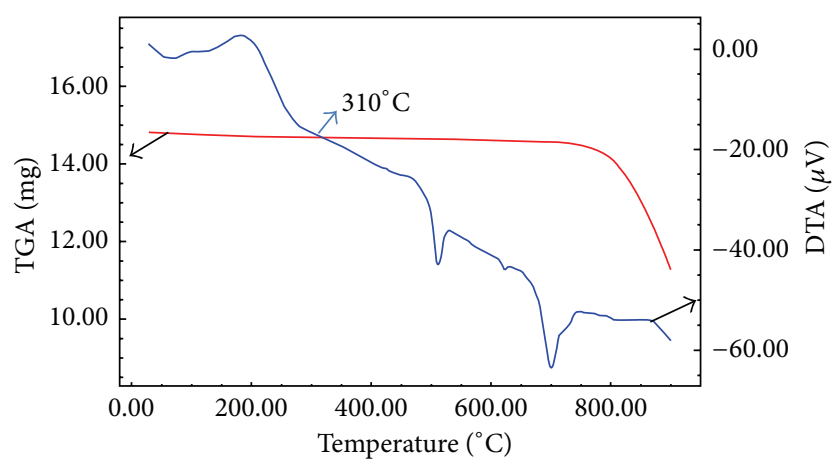

FIGURE 5: TG-DTA curves of $\mathrm{MoS}_{2}$ nanosheets.

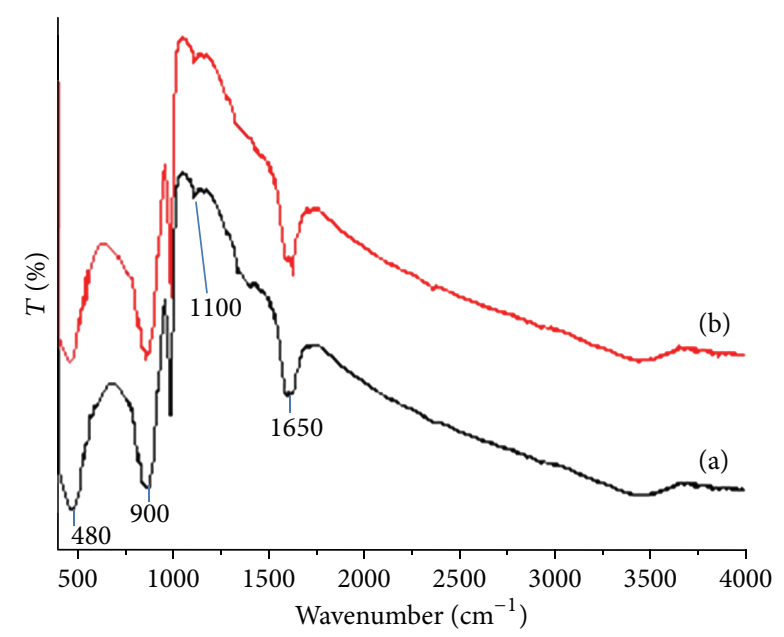

FIGURE 6: FT-IR spectra of $\mathrm{MoS}_{2}$ : (a) nanoflowers and (b) nanosheets.

TG-DTA curves of the $\mathrm{MoS}_{2}$ nanosheets are shown in Figure 5 . The nanosheets display $5 \%$ weight loss occurring above $730^{\circ} \mathrm{C}$ when heating to $900^{\circ} \mathrm{C}$ throughout the analysis. This can be attributed to dehydroxylation of the material, which is favorable for recrystallization and growth of the nanosheets. The prominent exothermic peaks at $495^{\circ} \mathrm{C}$ and $700^{\circ} \mathrm{C}$ correspond to the decomposition of surfactants and the sheet crystallization phase. As a result, the decomposition of physisorbed solvent occurred during the preparation using heat-assisted magnetic stirring. Furthermore, there is a possibility that recrystallization could occur above $800^{\circ} \mathrm{C}$, which reflects the stable state.

FT-IR spectra of the nanoflowers and nanosheets are shown in Figures 6(a) and 6(b). There are broad absorption bands at $480 \mathrm{~cm}^{-1}, 900 \mathrm{~cm}^{-1}, 1100 \mathrm{~cm}^{-1}$, and $1650 \mathrm{~cm}^{-1}$ for both samples. The band at $480 \mathrm{~cm}^{-1}$ is due to the Mo-S bond, and that at $900 \mathrm{~cm}^{-1}$ is due to the S-S bond [36]. The absorption band between $1100 \mathrm{~cm}^{-1}$ and $1650 \mathrm{~cm}^{-1}$ is ascribed to the stretching vibrations of the hydroxyl group and Mo-O vibrations [36]. The absorption band at $3500 \mathrm{~cm}^{-1}$ formed by the stretching vibration of hydroxyls vanished in the nanosheet sample, which was confirmed by the TG-DTA curve (Figure 5).

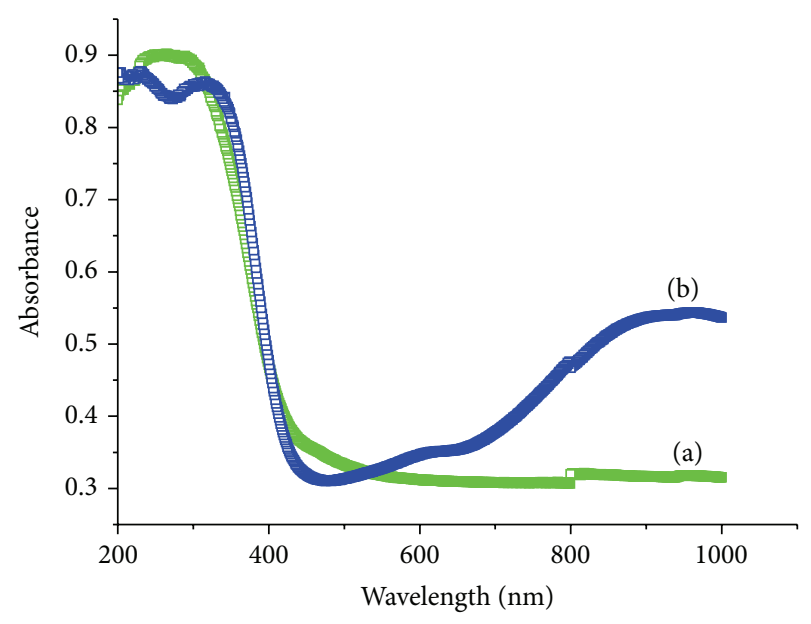

FIGURE 7: UV-Vis spectra of $\mathrm{MoS}_{2}$ : (a) nanoflowers and (b) nanosheets.

The UV-Vis optical absorption spectra were recorded at room temperature in the wavelength region of $250-750 \mathrm{~nm}$, as shown in Figures 7(a) and 7(b). The nanoflowers and nanosheets have strong absorption in the visible-light region. However, the absorption of the nanosheets compared to nanoflowers is stronger due to the higher light harvesting behavior of nanosheets with active edge sites. The absorption bands appeared at 340 and $610 \mathrm{~nm}$, which are attributed to the direct excitonic transition at the $K$ and $M$ point of the Brillouin zone [37]. The indirect band gap was calculated by the Tauc equation using the optical absorption data near the band edge [38, 39]:

$$
(\alpha h v)^{1 / 2}=A\left(h v-E_{g}\right),
$$

where $\alpha$ is the absorbance, $h \nu$ is the incident photon energy, and $A$ is a constant. The band gaps $\left(E_{g}\right)$ are determined by linear fit extrapolation onto the $x$-axis. A plot of $(\alpha h \nu)^{1 / 2}$ versus photon energy $(h \nu)$ gives the band energies of the nanoflowers and nanosheets by the intercept of the tangent to the $x$-axis, as shown in Figures $8(\mathrm{a})$ and $8(\mathrm{~b})$. The band energies of the $\mathrm{MoS}_{2}$ nanoflowers and nanosheets were estimated to be 2.72 and $2.83 \mathrm{eV}$, respectively, which are fairly close to earlier reports $[37,40]$.

The agglomeration and stability of nanomaterials are quantified based on the zeta potential absolute value, which designates the static repellency of nanomaterials dispensed in oil, as shown in Figure 9. The maximum zeta potential absolute value of the nanoflowers and nanosheets in oil was obtained at $0.1 \mathrm{wt} \%$, which is ascribed to the optimum concentration with maximum stability of the nanosheets in the base oil. The bigger value designates improved dispersion of the nanomaterials in the base oil. If the absolute value of zeta potential is higher than $30 \mathrm{mV}$, then the nanofluid becomes stable [41]. For nanoflowers and nanosheets dispersed oils, the absolute values of zeta potential are 32 and $34 \mathrm{mV}$, respectively. Thus, the stability of both oils is indicated to be good. In the case of nanosheets dispersed oil, the zeta potential of $0.6 \mathrm{wt} \%$ concentration is shown to be smaller than $1 \mathrm{wt} \%$ due 


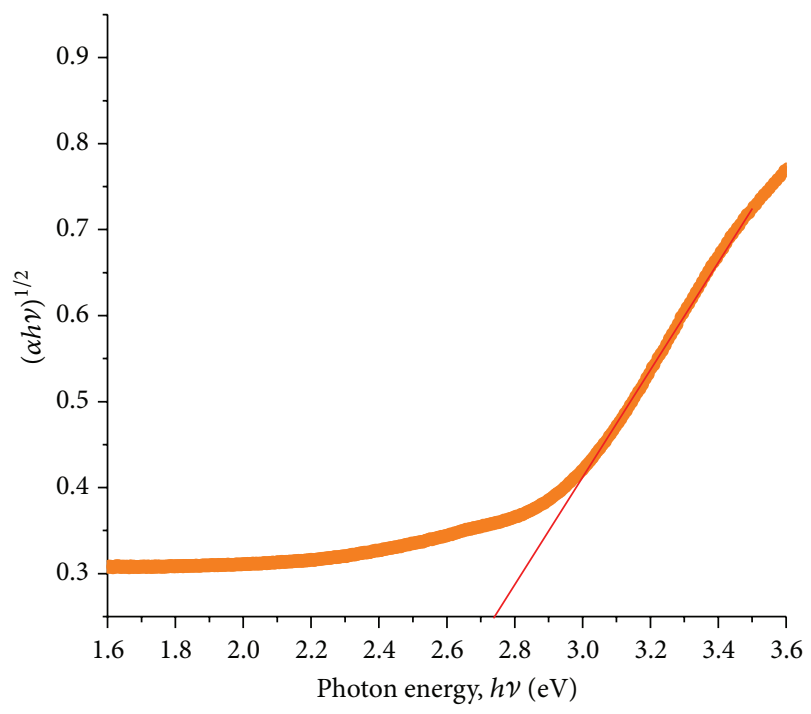

(a)

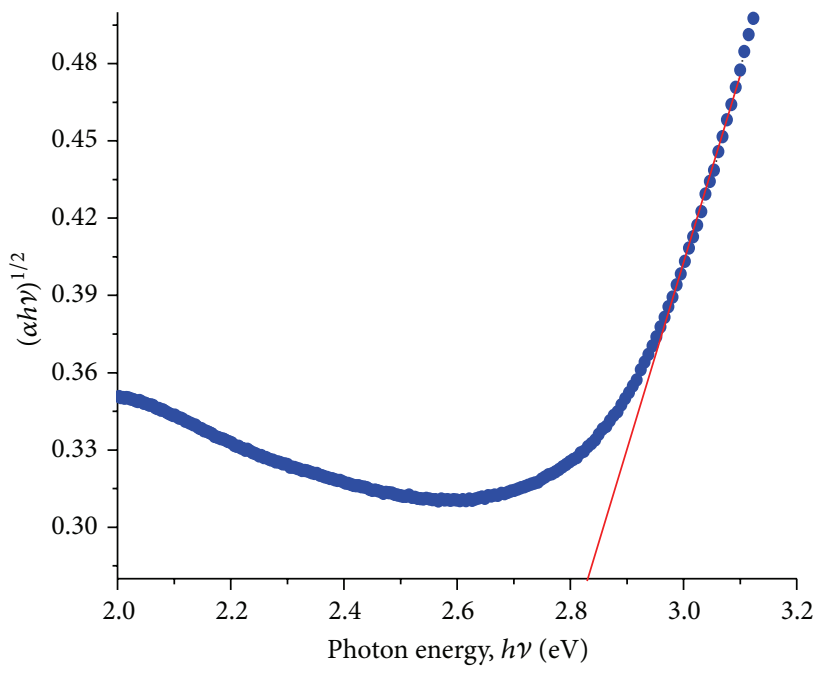

(b)

FIgURE 8: Tauc plots of $\mathrm{MoS}_{2}$ : (a) nanoflowers and (b) nanosheets.

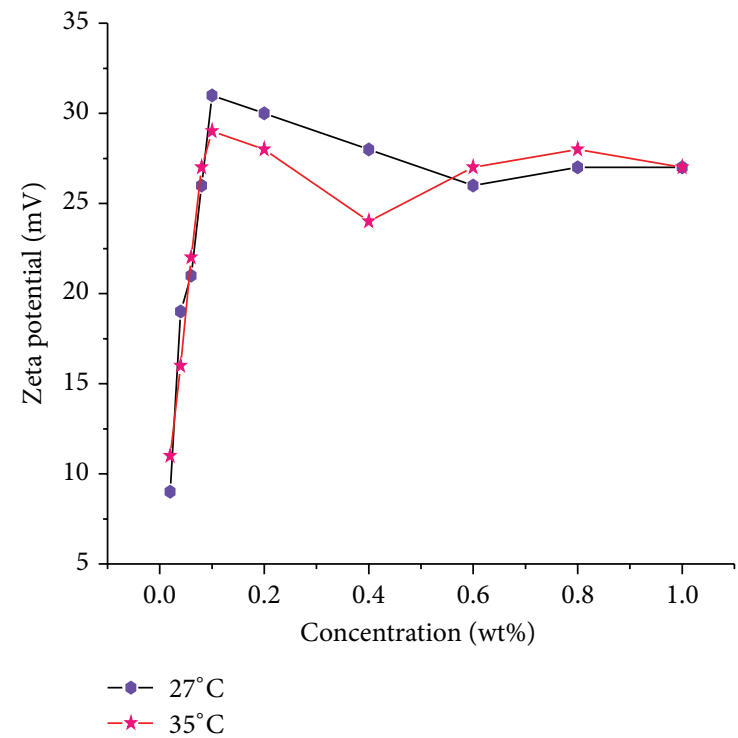

(a)

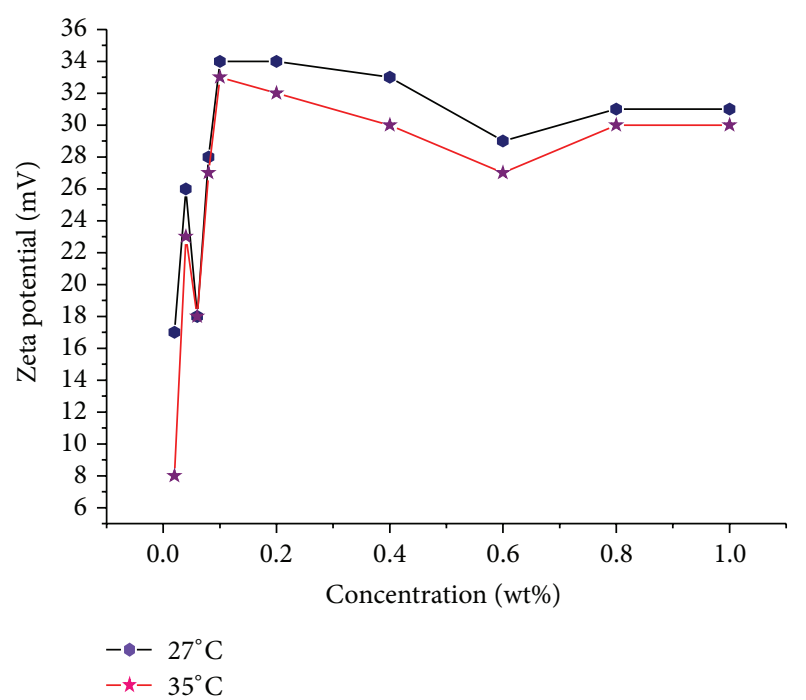

(b)

Figure 9: Variation of zeta potential with $\mathrm{MoS}_{2}$ (a) nanoflowers and (b) nanosheets for different concentration at $27^{\circ} \mathrm{C}$ and $35^{\circ} \mathrm{C}$.

to low $\mathrm{pH}$ value of the oil. Therefore, the zeta potential is related with corresponding $\mathrm{pH}$ of the nanoparticles dispersed oils. The dispersion nature of nanoadditives in oils depends on process parameters such as the type, concentration (wt\% of nanoparticles), and nature of the base oil and temperature. Figure 10 shows the viscosity of the base oil and oils with $0.1 \mathrm{wt} \%$ of nanoflowers and nanosheets added was estimated in the temperature range of room temperature to $120^{\circ} \mathrm{C}$. In all cases, the viscosity of lubricant decreases with increasing temperature. In addition, the viscosity increases by $20 \%$ for oil with nanoflowers and nanosheets added compared to the base oil at the elevated temperature, and no significant change of viscosity was observed with the different morphologies of these nanomaterials.

Figure 11 shows the friction coefficient as a function of time with different concentrations of nanoflowers and nanosheets in oil. This data was obtained using a four-ball test with a $40 \mathrm{Kgf}$ load and a speed of $1000 \mathrm{rpm}$ for 60 minutes. The friction coefficient of the pure base oil without any additives increases with the applied load. Furthermore, the friction coefficient of the base oil containing nanoflowers or nanosheets is always lower than that of the pure base oil. On the other hand, the base oil containing nanosheets exhibits a lower friction coefficient than that with nanoflowers. 


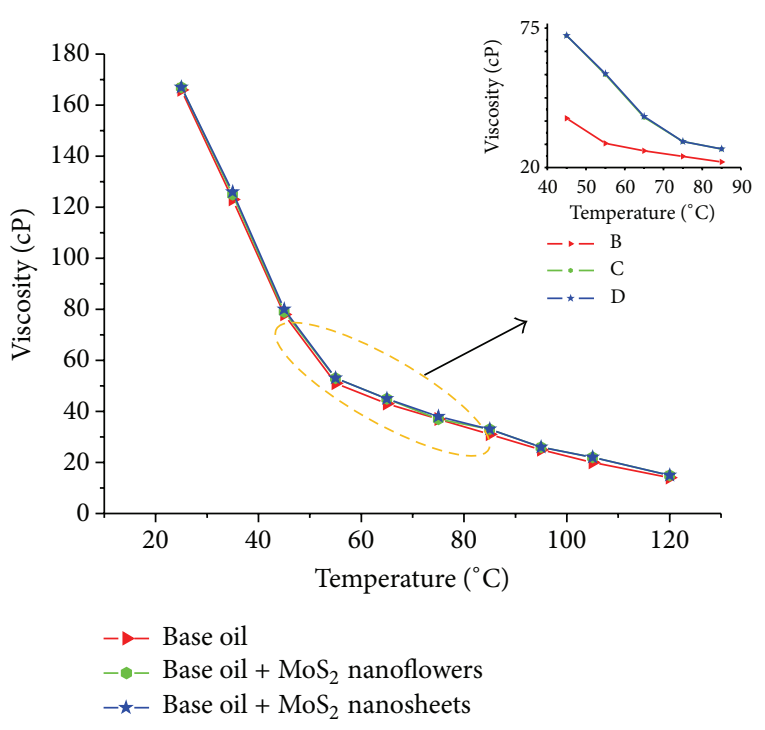

FIGURE 10: Variation of viscosity with respect to temperature.

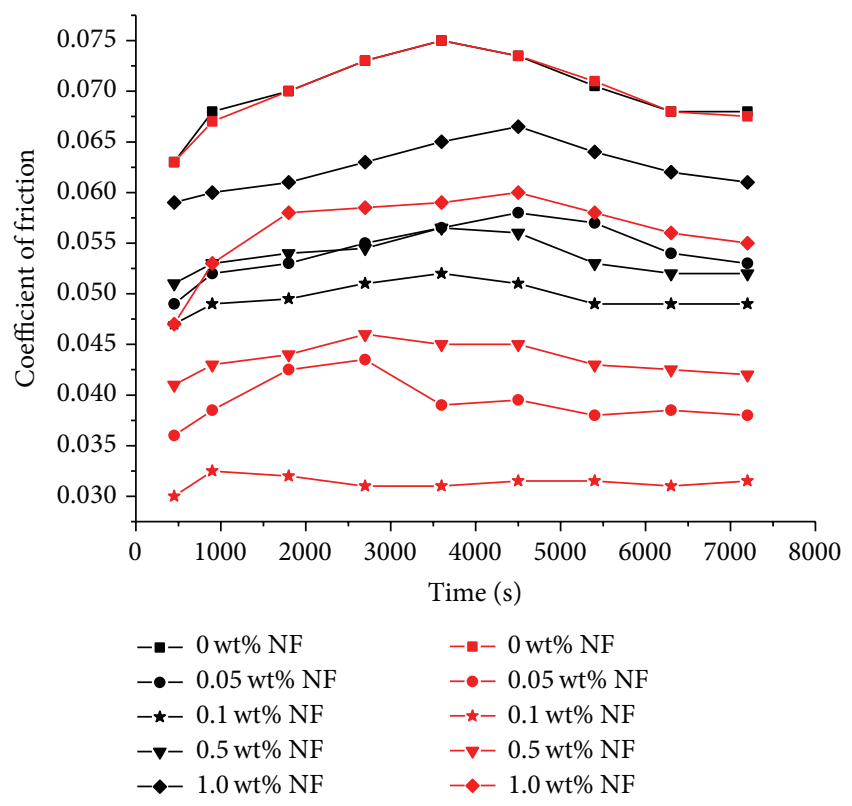

FIGURE 11: Friction coefficient curves of different concentrations of $\mathrm{MoS}_{2}$ nanoflowers (black color line) and nanosheets (red color line) with respect to time.

This is due to the slippage of nanosheets at asperities and deformation into individual nanosheets to form a tribofilm at the interfaces, which reduces the coefficient of friction. The friction coefficient $(\mu)$ is equal to $T \sqrt{ } 6 / 3 W r$, where $T$ is the frictional torque in $\mathrm{kg} \mathrm{mm}, W$ is the normal load in $\mathrm{kg}$, and $r$ is the distance between the center of the interface on the lower balls and the axis of rotation $[42,43]$.

To evaluate the wear-resistance tribological properties of the $\mathrm{MoS}_{2}$ nanomaterials, a noncontact universal surface profilometer was used to measure the wear scar and debris of the balls. Figure 12 shows the micrographs of worn surfaces produced after the $1 \mathrm{~h}$ tests with lubrication using the nanoflowers and nanosheets. Negligible wear scar for the steel balls was observed during these experiments for oil containing $0.1 \mathrm{wt} \%$ nanoflowers and nanosheets. There is a clean film on the surface of the steel balls, and in the case of nanosheets dispersed in oil, the tested balls have greater film formation than the nanoflower oil. The base oil with nanosheets is easily adherent and causes plastic deformation due to the contact pressure. The formation of tribofilm containing nanosheets supports reducing the friction due to slippage of the individual layers of nanosheets.

Interestingly, the average surface roughness $\left(R_{a}\right)$ value of the nanoflowers and nanosheets dispersed in oils remained constant as a function of the normal load. $R_{a}$ of the wear scars of the nanoflower and nanosheet oils were low: approximately 85.3 and $54.2 \mathrm{~nm}$, respectively, as shown in Figure 12. The results suggest some fracture occurs due to adhesive wear upon continuous sliding friction under the applied load. This proves that the base oils with nanoflowers and nanosheets have better antiwear capability than the pure base oil. $\mathrm{MoS}_{2}$ nanomaterials can easily react and form an abrasion-resistant protective film at contact interfaces due to high surface energy with many dangling bonds [16]. A firm boundary lubrication effect between the friction pairs occurs when protective tribofilms formed. This may yield a good ability to resist the shear failure due to fine lubricity. The friction coefficient thus declines distinctly, and the surface quality of the contact elements improves greatly, as shown in Figures 12(a) and 12(b).

SEM micrographs (Figures 13(a), 13(b), and 13(c)) show the wear scars of the base oil with and without nanoflowers or nanosheets. The rubbed surface was lubricated by the base oil and had many wide and deep ruts compared to the nanoflowers and nanosheets oils. We believe that the many regular nanosheets penetrate more easily into the interface with the lubricant than the nanoflowers. The nanosheets could form a continuous film on the rubbing surfaces due to strong adherence to contacts and enhance the tribological properties. The nanoflowers are so small that they can easily go into worn areas under compressive stress and perturb the hydrodynamic regime. Because of this, a higher coefficient of friction was obtained for nanoflowers rather than nanosheets, which is in good agreement with Figure 11.

The presence and formation of a tribofilm on the worn surface were examined with EDS for base oil containing $0.1 \mathrm{wt} \%$ nanoflowers and nanosheets, as shown in Figures 13(d), 13(e), and 13(f). Mo-S signals detected on the worn surface indicate that the $\mathrm{MoS}_{2}$ nanomaterials settle and fill the furrows on the worn surface, although the Mo-S signal is much weaker than the Fe signal on the ball surface. Moreover, the surface scratches and the furrows became vanished. Both the friction coefficient and the wear scar diameter were minimal. In both cases (i.e., nanoflowers and nanosheets), the surface edges were slightly ragged and obscured by metal particles at normal loads greater than $40 \mathrm{Kgf}$. As a result, worn surfaces revealed abrasive wear and no severe adhesive wear was noticed.

The superior friction reduction and antiwear behavior of $\mathrm{MoS}_{2}$ nanoflowers and nanosheets dispersed in oil compared 

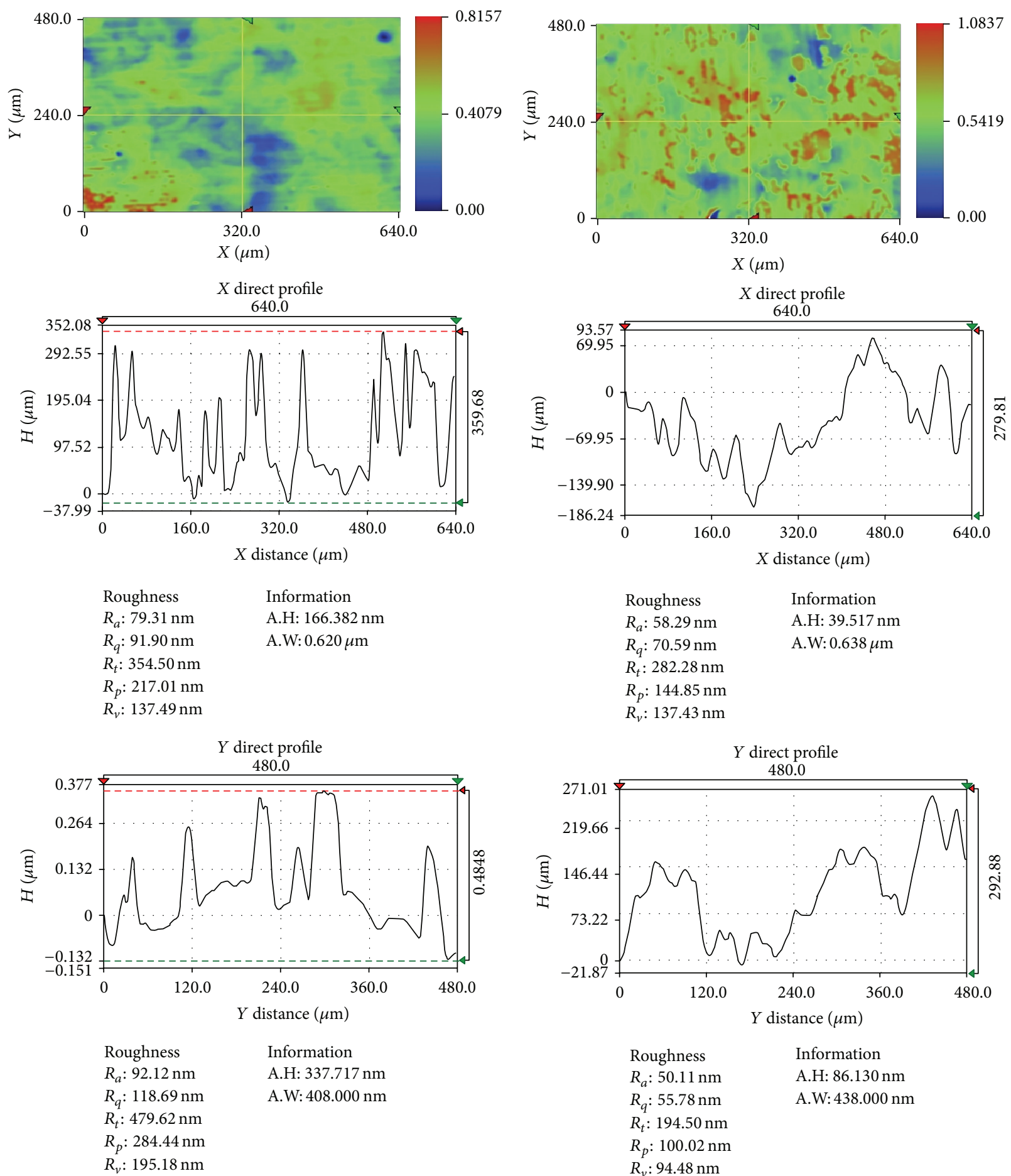

(a)
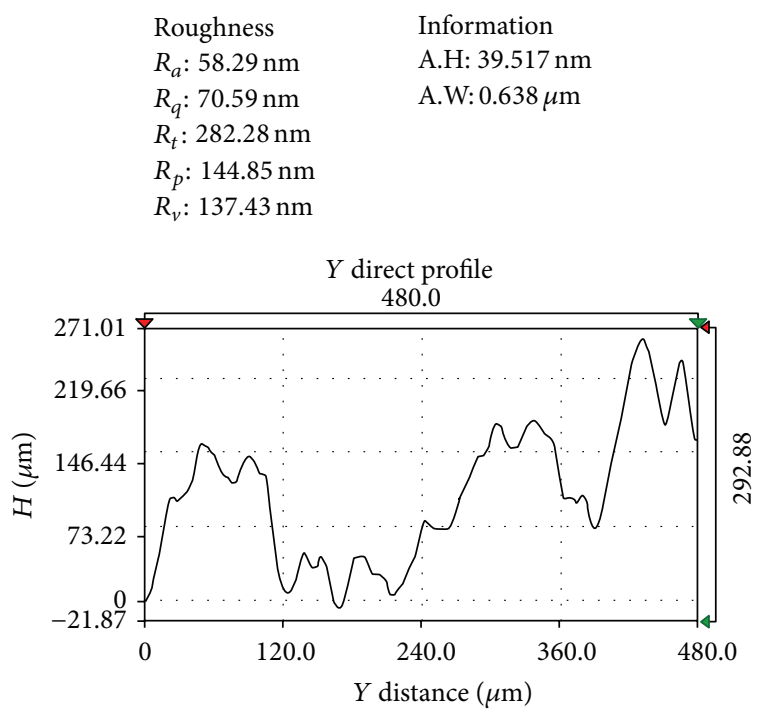

$\begin{array}{ll}\text { Roughness } & \text { Information } \\ R_{a}: 50.11 \mathrm{~nm} & \text { A.H: } 86.130 \mathrm{~nm} \\ R_{q}: 55.78 \mathrm{~nm} & \text { A.W: } 438.000 \mathrm{~nm} \\ R_{t}: 194.50 \mathrm{~nm} & \\ R_{p}: 100.02 \mathrm{~nm} & \\ R_{v}: 94.48 \mathrm{~nm} & \end{array}$

(b)

FIGURE 12: Noncontact optical profile testing apparatus images of wear scar at $1000 \mathrm{rpm}$ under $40 \mathrm{Kgf}$ loads for $1 \mathrm{~h}$ : (a) base oil with $\mathrm{MoS}_{2}$ nanoflowers and (b) base oil with $1.0 \mathrm{wt} \% \mathrm{MoS}_{2}$ nanosheets.

to pristine oil are attributed to development of tribofilms between the contact interfaces $[10,12,13,20]$. The wear mechanism of $\mathrm{MoS}_{2}$ nanosheets is ascribed to separation of interlayers into individual layers due to weaker van der Waals or Coulombic repulsive interaction at contact pressure
$[13,25,26]$. This mechanism helps to form a tribofilm and adhere at counter parts, enhancing the tribological properties which are confirmed with 3D topography results (Figure 12). The tribological properties with dispersion of $\mathrm{MoS}_{2}$ additives in oil are improved. The worn surface of the upper ball 


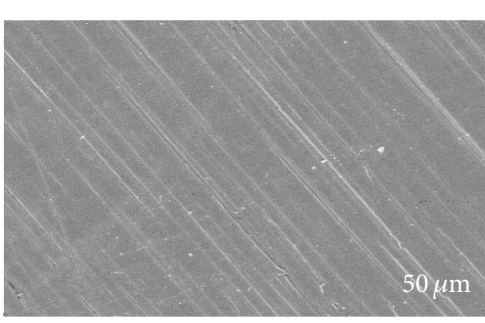

(a)

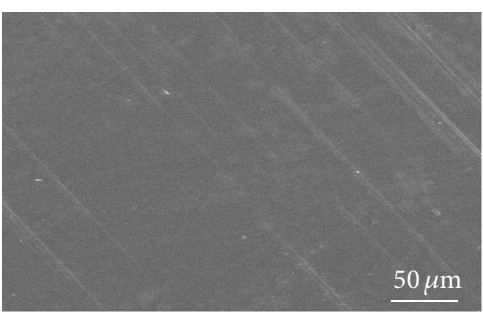

(b)

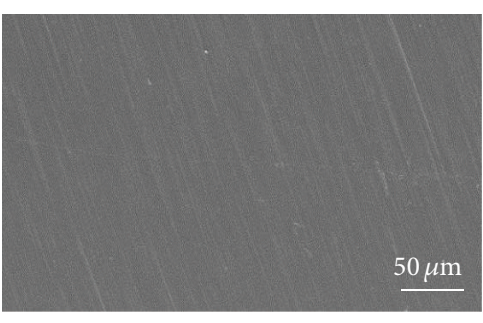

(c)

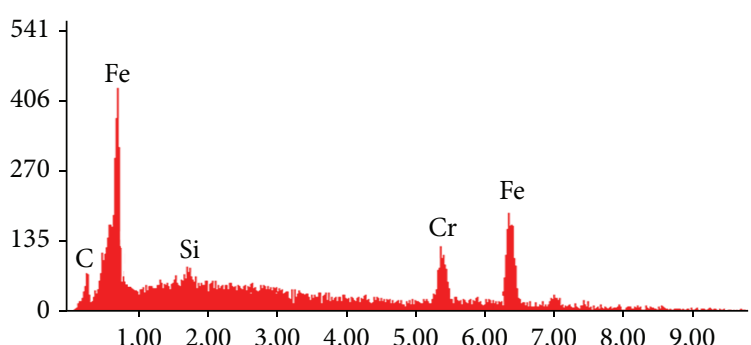

(d)

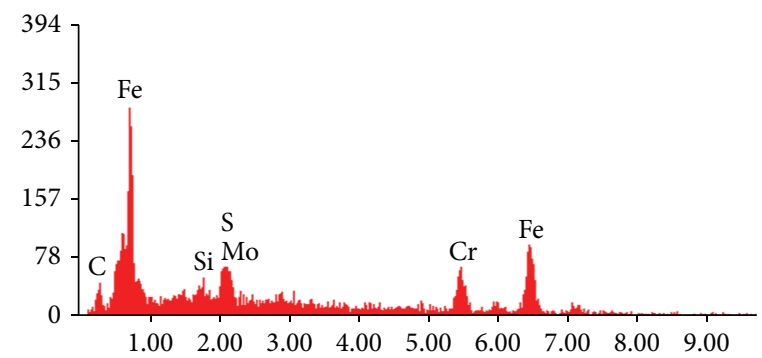

(e)

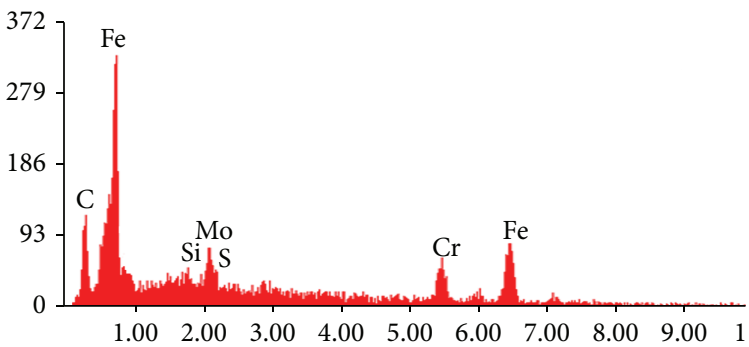

(f)

FIGURE 13: Wear scar of upper ball on contacted surface with different conditions: (a) base oil, (b) base oil with 0.1 wt $\%$ MoS $_{2}$ nanoflowers, and (c) base oil with $0.1 \mathrm{wt} \% \mathrm{MoS}_{2}$ nanosheets. (d), (e), and (f) represent EDS spectra of (a), (b), and (c) conditions, respectively.

showed metal-to-metal contact at interfaces. Therefore, the nanosheets could reduce the coefficient of friction, since the metal-to-metal contact is smaller than when nanoflowers were used. Presumably, these results indicated that the nanosheets are more suitable and helped the lubricant to adsorb onto the metal surface very well, which reduced the friction.

\section{Conclusions}

We report the solvothermal synthesis of $\mathrm{MoS}_{2}$ nanoflowers and nanosheets using thioacetamide and thiourea as sulfur source, respectively. The method presented enables largescale production of unique and controllable morphologies by suitable selection of the surfactant. The effects and nature of morphology on the tribological properties have been presented. Substantial friction and wear reduction was achieved in boundary lubrication, and the beneficial effects are attributed to the nanosheets rather than nanoflowers when added to the lubricant oil. The results revealed tribological effect of engine oil without additive and presence of nanoflowers and nanosheets.
From the friction tests, the performance of lubricating oil using these synthesized $\mathrm{MoS}_{2}$ materials as additives is investigated using the four-ball test and results show that the optimal additive concentration of nanoflowers and nanosheets is $0.1 \mathrm{wt} \%$. The friction test results revealed that the average friction coefficient was two times lower for the nanosheets than for the nanoflowers. It was concluded that the significant improvement in tribological properties of oil with nanoflowers and nanosheets additives was due to the beneficial tribofilm transferred on the contact surfaces when particles entered the wear regime as evident from SEM and EDS studies.

The surface roughness analyses reveal that the roughness of the friction surface is reduced and the surface gets smoother when $\mathrm{MoS}_{2}$ materials at optimum concentration level are added to the lubricants. It was also concluded that, as the benefits of exfoliation mechanism, the nanoflowers and nanosheets act as reservoir of low friction layers which cover the interface surfaces with a thickness of a few monolayers. Therefore, nanoflowers and nanosheets used as lubricating oil additives exhibit wear reduction characteristics. The unique mechanical and tribological properties indicate that the $\mathrm{MoS}_{2}$ 
nanosheets are a promising material for autolocomotive applications and help to contribute to successful commercialization of hybrid lubricants.

\section{Conflict of Interests}

The authors declare that there is no conflict of interests regarding the publication of this paper.

\section{Acknowledgments}

This research was supported by the Basic Science Research Program through the National Research Foundation of Korea (NRF) and funded by the Ministry of Science, ICT, and Future Planning (2014R1A2A2A01007081).

\section{References}

[1] Z. Yu, L. Tetard, L. Zhai, and J. Thomas, "Supercapacitor electrode materials: nanostructures from 0 to 3 dimensions," Energy \& Environmental Science, vol. 8, no. 3, pp. 702-730, 2015.

[2] X.-R. Wang, Y. Shi, and R. Zhang, "Field-effect transistors based on two-dimensional materials for logic applications," Chinese Physics B, vol. 22, no. 9, Article ID 098505, 2013.

[3] W. E. Buhro and V. L. Colvin, "Semiconductor nanocrystals: shape matters," Nature Materials, vol. 2, pp. 138-139, 2003.

[4] Y. Jung, J. Shen, and J. J. Cha, "Surface effects on electronic transport of 2D chalcogenide thin films and nanostructures," Nano Convergence, vol. 1, article 18, 8 pages, 2014.

[5] C. Tan and H. Zhang, "Two-dimensional transition metal dichalcogenide nanosheet-based composites," Chemical Society Reviews, vol. 44, no. 9, pp. 2713-2731, 2015.

[6] K. P. Rao and C. L. Xie, "A comparative study on the performance of boric acid with several conventional lubricants in metal forming processes," Tribology International, vol. 39, no. 7, pp. 663-668, 2006.

[7] J. Luo, M. H. Zhu, Y. D. Wang, J. F. Zheng, and J. L. Mo, "Study on rotational fretting wear of bonded $\mathrm{MoS}_{2}$ solid lubricant coating prepared on medium carbon steel," Tribology International, vol. 44, no. 11, pp. 1565-1570, 2011.

[8] F. A. Deorsola, N. Russo, G. A. Blengini, and D. Fino, "Synthesis, characterization and environmental assessment of nanosized $\mathrm{MoS}_{2}$ particles for lubricants applications," Chemical Engineering Journal, vol. 195-196, pp. 1-6, 2012.

[9] I. Efeoglu, Ö. Baran, F. Yetim, and S. Altintaş, "Tribological characteristics of $\mathrm{MoS}_{2}-\mathrm{Nb}$ solid lubricant film in different tribo-test conditions," Surface and Coatings Technology, vol. 203, no. 5-7, pp. 766-770, 2008.

[10] I. Lahouij, B. Vacher, J.-M. Martin, and F. Dassenoy, "IF-MoS based lubricants: influence of size, shape and crystal structure," Wear, vol. 296, pp. 558-567, 2012.

[11] R. Tenne, L. Margulis, M. Genut, and G. Hodes, "Polyhedral and cylindrical structures of $\mathrm{WS}_{2}$," Nature, vol. 360, pp. 444-446, 1992.

[12] R. R. Sahoo and S. K. Biswas, "Effect of layered $\mathrm{MoS}_{2}$ nanoparticles on the frictional behavior and microstructure of lubricating greases," Tribology Letters, vol. 53, no. 1, pp. 157-171, 2014.

[13] G. Zhu, J. Sun, B. Wang, and Y. Wang, "Study on tribological properties of the rolling fluid containing nano- $\mathrm{MoS}_{2}$ for cold rolling of steel strip," China Petroleum Processing and Petrochemical Technology, vol. 13, no. 1, pp. 64-69, 2011.

[14] M. Praveena, V. Jayaram, and S. K. Biswas, "Friction between a steel ball and a steel flat lubricated by $\mathrm{MoS}_{2}$ particles suspended in hexadecane at $150{ }^{\circ} \mathrm{C}$," Industrial and Engineering Chemistry Research, vol. 51, no. 38, pp. 12321-12328, 2012.

[15] J. Kogovšek, M. Remškar, and M. Kalin, "Lubrication of DLCcoated surfaces with $\mathrm{MoS}_{2}$ nanotubes in all lubrication regimes: surface roughness and running-in effects," Wear, vol. 303, no. 12, pp. 361-370, 2013.

[16] Y. Feldman, E. Wasserman, D. J. Srolovitz, and R. Tenne, "Highrate, gas-phase growth of $\mathrm{MoS}_{2}$ nested inorganic fullerenes and nanotubes," Science, vol. 267, no. 5195, pp. 222-225, 1995.

[17] L. Margulis, G. Salitra, R. Tenne, and M. Talianker, "Nested fullerene-like structures," Nature, vol. 365, no. 6442, pp. 113-114, 1993.

[18] L. Rapoport, Y. Feldman, M. Homyonfer et al., "Inorganic fullerene-like material as additives to lubricants: structurefunction relationship," Wear, vol. 225-229, pp. 975-982, 1999.

[19] R. Greenberg, G. Halperin, I. Etsion, and R. Tenne, "The effect of $\mathrm{WS}_{2}$ nanoparticles on friction reduction in various lubrication regimes," Tribology Letters, vol. 17, no. 2, pp. 179-186, 2004.

[20] J. Tannous, F. Dassenoy, I. Lahouij et al., "Understanding the tribochemical mechanisms of IF- $\mathrm{MoS}_{2}$ nanoparticles under boundary lubrication," Tribology Letters, vol. 41, no. 1, pp. 5564, 2011.

[21] P. Rabaso, F. Ville, F. Dassenoy, J. M. Martin, and M. Diaby, "Tribological behaviour of fullerene-like MoS2 nanoparticles for different lubrication regimes in the presence of dispersants," in Proceedings of the 40th Leeds-Lyon Symposium on Tribology \& Tribochemistry Forum, Lyon, France, September 2013.

[22] L. Rapoport, Y. Bilik, Y. Feldman, M. Homyonfer, S. R. Cohen, and R. Tenne, "Hollow nanoparticles of $\mathrm{WS}_{2}$ as potential solidstate lubricants," Nature, vol. 387, no. 6635, pp. 791-793, 1997.

[23] L. Cizaire, B. Vacher, T. le Mogne et al., "Mechanisms of ultralow friction by hollow inorganic fullerene-like $\mathrm{MoS}_{2}$ nanoparticles," Surface and Coatings Technology, vol. 160, no. 2-3, pp. 282-287, 2002.

[24] L. Joly-Pottuz, F. Dassenoy, M. Belin, B. Vacher, J. M. Martin, and N. Fleischer, "Ultralow-friction and wear properties of IF$\mathrm{WS}_{2}$ under boundary lubrication," Tribology Letters, vol. 18, no. 4, pp. 477-485, 2005.

[25] R. Rosentsveig, A. Gorodnev, N. Feuerstein et al., "Fullerenelike $\mathrm{MoS}_{2}$ nanoparticles and their tribological behavior," Tribology Letters, vol. 36, no. 2, pp. 175-182, 2009.

[26] M. Kalin, J. Kogovšek, and M. Remškar, "Mechanisms and improvements in the friction and wear behavior using $\mathrm{MoS}_{2}$ nanotubes as potential oil additives," Wear, vol. 280-281, pp. 3645, 2012.

[27] A. Moshkovith, V. Perfiliev, A. Verdyan et al., "Sedimentation of IF-WS 2 aggregates and a reproducibility of the tribological data," Tribology International, vol. 40, no. 1, pp. 117-124, 2007.

[28] A. Moshkovith, V. Perfiliev, I. Lapsker, N. Fleischer, R. Tenne, and L. Rapoport, "Friction of fullerene-like $\mathrm{WS}_{2}$ nanoparticles: effect of agglomeration," Tribology Letters, vol. 24, no. 3, pp. 225228, 2006.

[29] M. Chhowalla and G. A. J. Amaratunga, "Thin films of fullerene-like $\mathrm{MoS}_{2}$ nanoparticles with ultra-low friction and wear," Nature, vol. 407, no. 6801, pp. 164-167, 2000.

[30] X. L. Li and Y. D. Li, "Formation of $\mathrm{MoS}_{2}$ inorganic fullerenes (IFs) by the reaction of $\mathrm{MoO}_{3}$ nanobelts and S," Chemistry-A European Journal, vol. 9, no. 12, pp. 2726-2731, 2003. 
[31] H. Tang, C. Li, X. Yang, C. Mo, K. Cao, and F. Yan, "Synthesis and tribological properties of $\mathrm{NbSe}_{3}$ nanofibers and $\mathrm{NbSe}_{2}$ microsheets," Crystal Research and Technology, vol. 46, no. 4, pp. 400-404, 2011.

[32] L. Rapoport, N. Fleischer, and R. Tenne, "Applications of $\mathrm{WS}_{2}$ $\left(\mathrm{MoS}_{2}\right)$ inorganic nanotubes and fullerene-like nanoparticles for solid lubrication and for structural nanocomposites," Journal of Materials Chemistry, vol. 15, no. 18, pp. 1782-1788, 2005.

[33] I. Uzcanga, I. Bezverkhyy, P. Afanasiev, C. Scott, and M. Vrinat, "Sonochemical preparation of $\mathrm{MoS}_{2}$ in aqueous solution: replication of the cavitation bubbles in an inorganic material morphology," Chemistry of Materials, vol. 17, no. 14, pp. 35753577, 2005.

[34] G. Santillo, F. A. Deorsola, S. Bensaid, N. Russo, and D. Fino, "Sonochemical preparation of $\mathrm{MoS}_{2}$ in aqueous solution: replication of the cavitation bubbles in an inorganic material morphology," Chemical Engineering Journal, vol. 207-208, no. 1, pp. 322-328, 2012.

[35] H. Akram, C. Mateos-Pedrero, E. Gallegos-Suárez, A. GuerreroRuíz, T. Chafik, and I. Rodríguez-Ramos, "Effect of electrolytes nature and concentration on the morphology and structure of $\mathrm{MoS}_{2}$ nanomaterials prepared using one-pot solvothermal method," Applied Surface Science, vol. 307, pp. 319-326, 2014.

[36] G. Nagaraju, C. N. Tharamani, G. T. Chandrappa, and J. Livage, "Hydrothermal synthesis of amorphous $\mathrm{MoS}_{2}$ nanofiber bundles via acidification of ammonium heptamolybdate tetrahydrate," Nanoscale Research Letters, vol. 2, no. 9, pp. 461-468, 2007.

[37] E. P. Nguyen, B. J. Carey, T. Daeneke et al., "Investigation of twosolvent grinding-assisted liquid phase exfoliation of layered $\mathrm{MoS}_{2}$," Chemistry of Materials, vol. 27, no. 1, pp. 53-59, 2015.

[38] S. K. Bhar, N. Mukherjee, S. K. Maji, B. Adhikary, and A. Mondal, "Synthesis of nanocrystalline iron oxide ultrathin films by thermal decomposition of iron nitropruside: structural and optical properties," Materials Research Bulletin, vol. 45, no. 12, pp. 1948-1953, 2010.

[39] L. Diamandescu, F. Vasiliu, D. Tarabasanu-Mihaila et al., "Structural and photocatalytic properties of iron- and europiumdoped $\mathrm{TiO}_{2}$ nanoparticles obtained under hydrothermal conditions," Materials Chemistry and Physics, vol. 112, no. 1, pp. 146$153,2008$.

[40] M. Zhong, Z. Wei, X. Meng, F. Wu, and J. Li, "From $\mathrm{MoS}_{2}$ microspheres to $\alpha-\mathrm{MoO}_{3}$ nanoplates: growth mechanism and photocatalytic activities," European Journal of Inorganic Chemistry, no. 20, pp. 3245-3251, 2014.

[41] J.-H. Lee, K. S. Hwang, S. P. Jang et al., "Effective viscosities and thermal conductivities of aqueous nanofluids containing low volume concentrations of $\mathrm{Al}_{2} \mathrm{O}_{3}$ nanoparticles," International Journal of Heat and Mass Transfer, vol. 51, no. 11-12, pp. 26512656, 2008.

[42] T. C. Ing, A. K. Mohammed Rafiq, Y. Azli, and S. Syahrullail, "The effect of temperature on the tribological behavior of RBD palm stearin," Tribology Transactions, vol. 55, no. 5, pp. 539-548, 2012.

[43] J. M. Thorp, "Four-ball assessment of deep drawing oils," Wear, vol. 33, no. 1, pp. 93-108, 1975. 

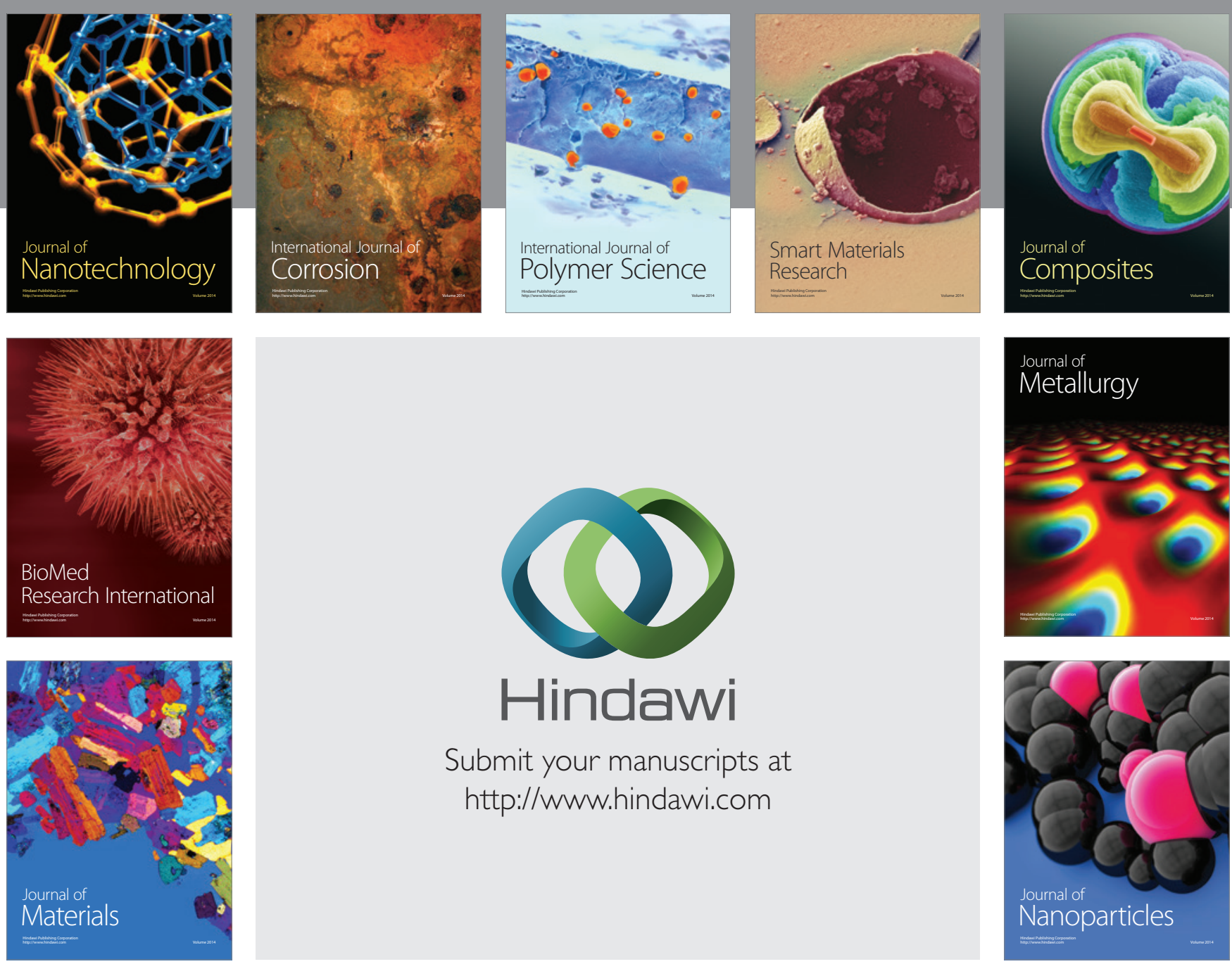

Submit your manuscripts at http://www.hindawi.com
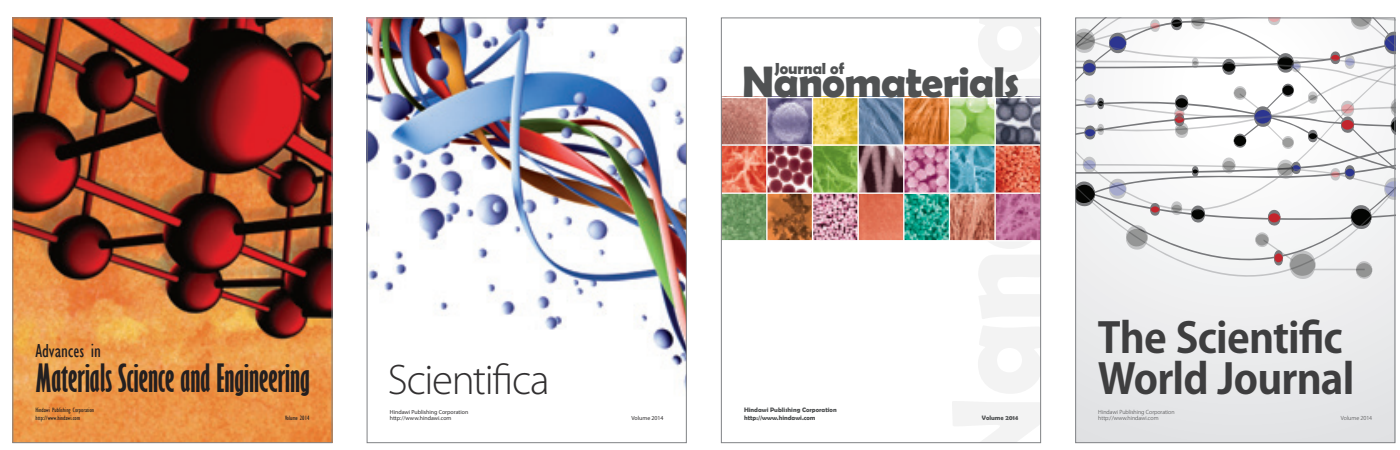

\section{The Scientific World Journal}
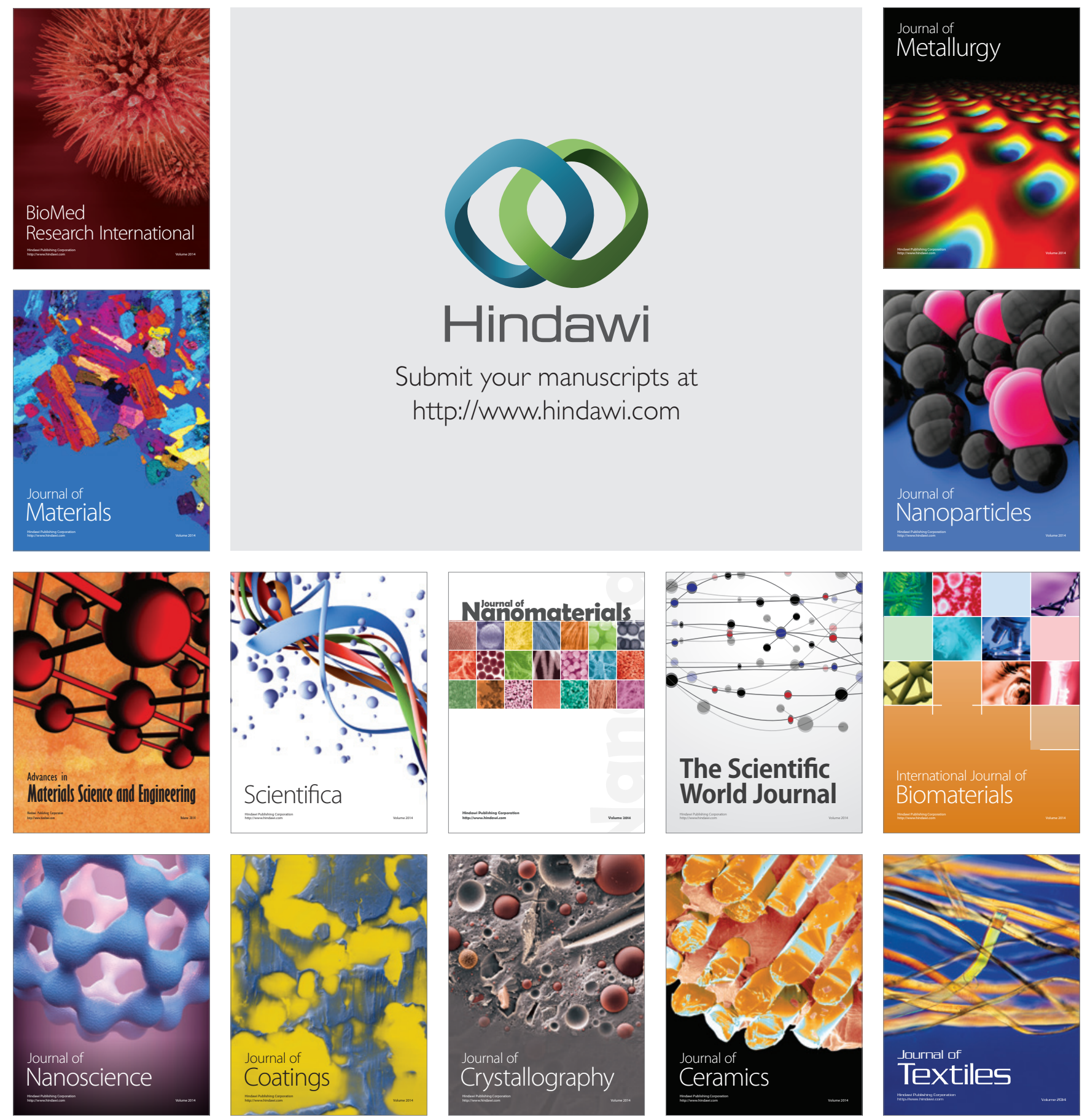